\title{
Exposure to severe famine in the prenatal or postnatal period and the development of diabetes in adulthood: an observational study
}

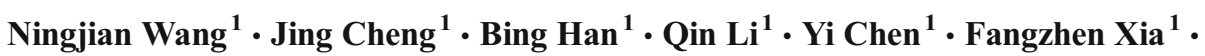 \\ Boren Jiang $^{1} \cdot$ Michael D. Jensen ${ }^{2} \cdot$ Yingli Lu $^{1}$
}

Received: 19 July 2016 / Accepted: 3 October 2016 / Published online: 2 November 2016

(C) Springer-Verlag Berlin Heidelberg 2016

\begin{abstract}
Aims/hypothesis Limited studies have compared the effect of prenatal or postnatal exposure to different severities of famine on the risk of developing diabetes. We aimed to measure the association between diabetes in adulthood and the exposure to different degrees of famine early in life (during the prenatal or postnatal period) during China's Great Famine (1959-1962). Methods Data from 3967 individuals were included (a total of 2115 individuals from areas severely affected by famine, 1858 from moderately affected areas, 6 excluded due to missing data). A total of 2335 famine-exposed individuals were further divided into those exposed during the fetal stage, childhood or adolescence/young adulthood. We constructed a differencein-differences model to compare $\mathrm{HbA}_{1 \mathrm{c}}$ and fasting plasma glucose among the participants exposed to different degrees of famine intensity at different life stages. Logistic analyses were used as measures of the association between diabetes and the different levels of famine severity at different life stages. Results Individuals who had been exposed to famine during the fetal period, childhood, and adolescence/adulthood and who had lived in a severely affected area had a $0.31 \%$,
\end{abstract}

Electronic supplementary material The online version of this article (doi:10.1007/s00125-016-4148-4) contains peer-reviewed but unedited supplementary material, which is available to authorised users.

Yingli Lu

luyingli2008@126.com

Michael D. Jensen

jensen@mayo.edu

1 Institute and Department of Endocrinology and Metabolism, Shanghai Ninth People's Hospital, Shanghai JiaoTong University School of Medicine, Shanghai 200011, People's Republic of China

2 Endocrine Research Unit, 5-194 Joseph, Mayo Clinic, Rochester, MN 55905, USA
$0.20 \%$ and $0.27 \%$ higher $\mathrm{HbA}_{1 \mathrm{c}}$, respectively, (all $p<0.01$ ) compared with unexposed individuals. After adjusting for age, sex, smoking status, education level and waist circumference, participants exposed to severe famine during the fetal stage (OR 1.90, 95\% CI 1.12, 3.21) and childhood (OR 1.44, $95 \%$ CI $1.06,1.97)$ had significantly higher odds estimates. Unexposed participants living in severely and moderately affected areas had a comparable prevalence of diabetes (OR $1.22,95 \%$ CI $0.80,1.87)$. A significant interaction between famine exposure during the fetal and childhood periods and the level of severity in the area of exposure was found $(p<0.05)$.

Conclusions/interpretation Exposure to severe famine in the fetal or childhood period may predict a higher $\mathrm{HbA}_{1 \mathrm{c}}$ and an increased diabetes risk in adulthood. These results from China indicate that both the prenatal and postnatal period may offer critical time windows for the determination of the risk of diabetes.

Keywords Diabetes $\cdot$ Famine $\cdot$ Postnatal period $\cdot$ Prenatal period $\cdot$ Severity

$\begin{array}{ll}\text { Abbreviations } \\ \text { DID } & \text { Difference-in-differences } \\ \text { FPG } & \text { Fasting plasma glucose } \\ \text { SPECT- } & \text { Survey on Prevalence in East China for } \\ \text { China } & \text { Metabolic Diseases and Risk Factors }\end{array}$

\section{Introduction}

Diabetes is an important cause of mortality and morbidity worldwide [1]. It has become pandemic in some developing countries. According to data from 2008, individuals in China 
and India accounted for $40 \%$ of the global population with diabetes (approximately 138 million individuals) and those in the USA and Russia accounted for 10\% (approximately 36 million individuals) [2]. More recent data indicate that the prevalence of diabetes in Chinese adults has increased to $11.6 \%$ [3]. The emerging pandemic is partly driven by population growth, ageing and diet and lifestyle changes, as well as by the greater longevity of individuals with diabetes [2, 4]. However, the results of our previous studies suggest that prenatal and early postnatal exposure to famine might also play an important role in the development of metabolic diseases, including diabetes [5] and fatty liver disease [6], consistent with the results of other studies [4, 7-9].

The developmental origins of health and disease theory hold that responsiveness to malnutrition early in life leads to metabolic and structural changes that might be useful for survival in early life but might also increase the risk of some noncommunicable diseases in later life [10]. Observations of the aftermath of famines offer a unique chance to understand the association between famine exposure early in life and the development of diabetes in adulthood. Examining data from the Ukraine famine of 1932-1933, Lumey et al found a doseresponse relationship between famine severity during prenatal development and the risk of diabetes later in life [4]. However, a postnatal exposure effect was not detected. A study of the 1944-1945 Dutch famine also indicated that self-reported undernutrition during childhood was associated with diabetes in a dose-dependent manner [8], although self-reported information may be limited by its subjective nature and the inability of individuals to report prenatal exposure. China's Great Famine of 1959-1962 is considered to be the largest and most severe famine of the 20th century [11], resulting in approximately 30 million excess deaths [12]. Previous studies have explored the association between famine exposure in early life and diabetes $[5,7]$ in the Chinese population but did not explicitly compare the effect of prenatal and postnatal exposure to different levels of famine severity on the risk of developing diabetes in adulthood.

Using the most recent data from the Survey on Prevalence in East China for Metabolic Diseases and Risk Factors (SPECT-China) from 2014 to 2015, we were able to determine whether prenatal or postnatal exposure to severe famine, compared with moderate famine, was associated with greater diabetes prevalence in adulthood, thus expanding our previous findings [5].

\section{Methods}

Study population SPECT-China was a cross-sectional investigation of the prevalence of metabolic diseases and risk factors in East China (www.chictr.org.cn registration no. ChiCTR-ECS-14005052). A stratified cluster sampling method was used. The sampling process was stratified according to rural/urban areas and economic status in Shanghai, Jiangxi Province and Zhejiang Province. The detailed sampling process has been described in previous studies $[5,13]$. This portion of the study was performed in 2014. In 2015 we studied data from the Anhui Province using the same scheme. Chinese adults aged 18 years and over who had lived at their current residence for 6 months or longer were selected and invited to participate in the study. Those with severe communication problems, acute illness or an unwillingness to participate were excluded. Anhui Province was the most severely affected area during China's Great Famine of 1959-1962, with an excess death rate of $475 \%$ [14]. Three rural sites were chosen and 2115 participants were recruited. We also selected rural sites in Shanghai and included 1858 participants in this moderately affected area, which had a death rate of $24 \%$ during the 1959-1962 famine [14]. In total, 3973 participants were selected. Finally, after excluding participants who had missing fasting plasma glucose (FPG) and $\mathrm{HbA}_{1 \mathrm{c}}$ results $(n=6), 3967$ participants were included in this famine exposure study (Fig. 1). The study protocol was approved by the Ethics Committee of Shanghai Ninth People's Hospital, Shanghai JiaoTong University School of Medicine. All procedures were performed in accordance with the ethical standards of the responsible committee on human experimentation (institutional and national) and with the Helsinki Declaration of 1975, as revised in 2008. Informed consent was obtained from all participants.

\section{Clinical, anthropometric and laboratory measurements A} questionnaire was used to collect information on participants' demographic characteristics, medical history and lifestyle risk factors. Current smoking was defined as having smoked at least 100 cigarettes in one's lifetime and currently smoking cigarettes [3]. Self-reported educational levels were categorised into low and high levels (socioeconomic status proxy). Blood pressure was measured using standard methods, described previously [3]. Waist circumference was measured at a point midway between the lowest rib and the iliac crest.

Venous blood samples were drawn after participants had fasted overnight for at least $8 \mathrm{~h}$. Blood samples for measuring FPG were collected into vacuum tubes containing the anticoagulant sodium fluoride and centrifuged within $1 \mathrm{~h}$ of collection. Blood samples were stored at $-20^{\circ} \mathrm{C}$ and were shipped by air within $2-4 \mathrm{~h}$ of collection, on dry ice, to a central laboratory certified by the College of American Pathologists. $\mathrm{HbA}_{1 \mathrm{c}}$ was assessed by high-performance liquid chromatography (MQ-2000PT; Medconn, Shanghai, China). FPG was measured with a Beckman Coulter AU 680 analyser (Beckman Coulter, Brea, USA). 

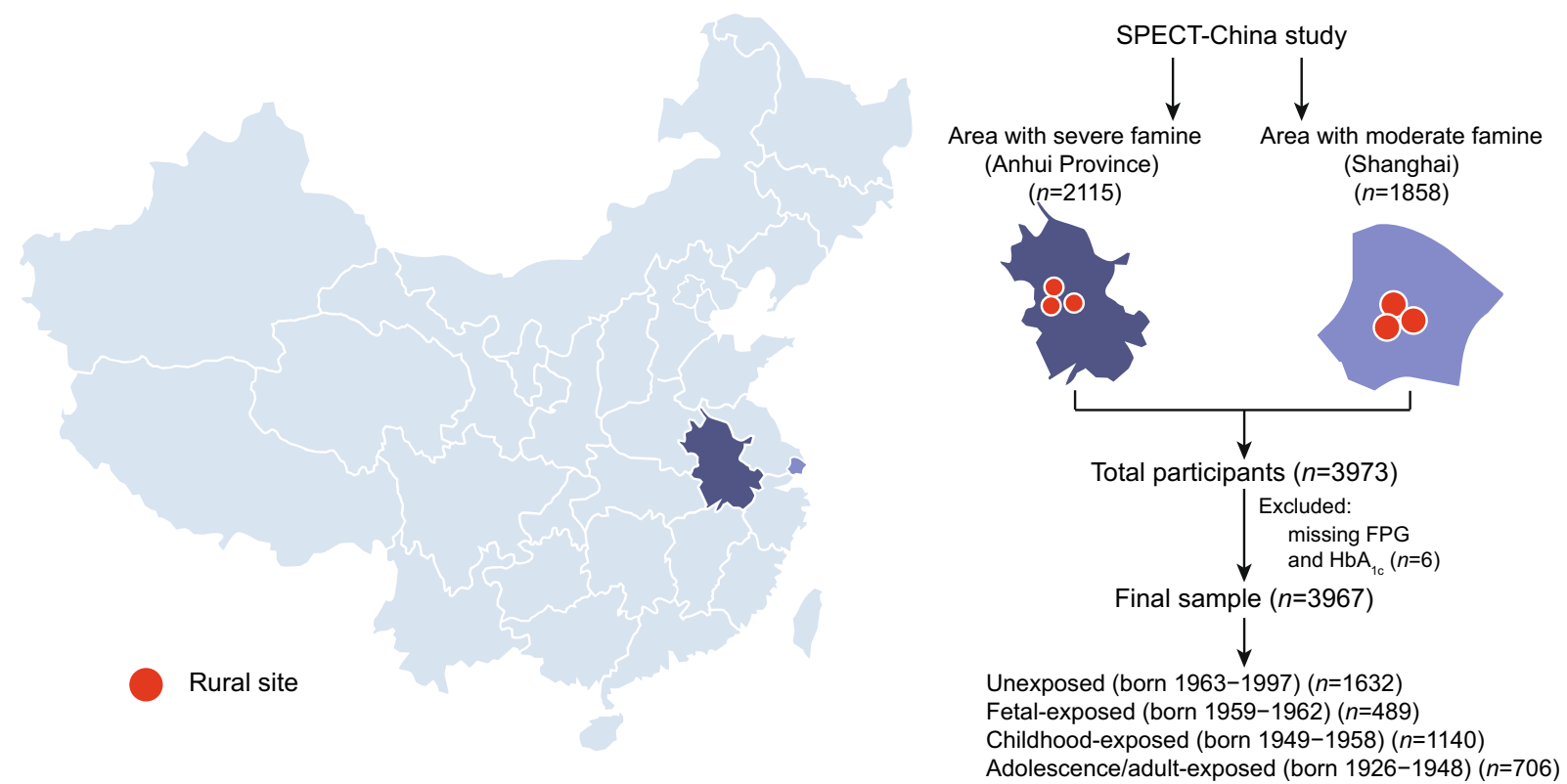

Fig. 1 Flowchart of participants selected from three rural locations in each of a representative moderately affected area (Shanghai) and a severely affected area (Anhui Province) of famine

Exposure age and area categories Exposure to famine was based on the year of birth. Similar to previous studies [5, 8], individuals were categorised according to their life stage at the time of exposure to famine (1 January 1959 to 31 December 1962). Exposure groups were as follows: fetal period (those born between 1959 and $1962[n=489]$ ); childhood (those born between 1949 and 1958 [ $n=1140]$ ); adolescence and young adulthood (those born between 1926 and 1948 $[n=706])$ and unexposed (those born between 1963 and $1997[n=1632])$.

As previously described, the excess death rate for each province was used to determine the famine severity [14] and was calculated as the change in mortality rate from the average level in 1956-1958 to the highest value in 1959-1962 [14]. Areas of famine were divided into severely (Anhui Province) and moderately (Shanghai) affected areas according to the excess death rates during the famine.

Definition of diabetes Diabetes was determined according to the American Diabetes Association 2014 criteria: a previous diagnosis by a healthcare professional; $\mathrm{FPG} \geq 7.0 \mathrm{mmol} / \mathrm{l}$ or $\mathrm{HbA}_{1 \mathrm{c}} \geq 6.5 \%$ (47.5 mmol/mol).

Statistical analysis IBM SPSS Statistics, Version 22 (IBM Corporation, Armonk, NY, USA) and Stata, Version 12.0 (StataCorp, College Station, TX, USA) were used to perform the analyses. All analyses were two-sided. A $p$ value of $<0.05$ indicated a significant difference. Continuous variables were expressed as means $\pm \mathrm{SD}$ and categorical variables as a percentage (\%). Participants' characteristics were compared by Student's $t$ test for continuous variables with a normal distribution, Mann-Whitney $U$ test for continuous variables with a skewed distribution and Pearson $\chi^{2}$ test for categorical variables.

To examine the relationship between the severity of famine exposure and the prevalence of diabetes in adulthood, a logistic regression analysis (backward stepwise) was used. The moderately affected famine group was the reference. Model 1 was adjusted for age and sex. Model 2 was further adjusted for current smoking and education level (low/high, socioeconomic status proxy). Model 3 was adjusted for the variables in model 2 and waist circumference (continuous variable). The results were expressed as OR $(95 \% \mathrm{CI})$. The interaction between the stage of life at which exposure to famine occurred and the severity of famine in the location of exposure was tested by using a multiplicative factor in the logistic regression model.

To increase the study power for comparing exposure groups, we also evaluated $\mathrm{HbA}_{1 \mathrm{c}}$ and FPG in individuals residing in the severely affected areas born during and before or after the famine and compared these differences with the corresponding differences for individuals residing in the moderately affected areas. This comparison produced the differencein-differences (DID) models [15]. Ordinary least-squares regressions were used, and the model was adjusted for age, sex, current smoking status, education level and waist circumference.

Finally, a sensitivity analysis was performed using finer age categories. The childhood-exposed group was split into early (born 1954-1958) and late (born 1949-1953) exposure groups. We excluded the group exposed in young adulthood and included only the group exposed in adolescence, born between 1963 and 1974, to narrow the age range. For the unexposed group, individuals aged $40-52$ years at the time 
of the study, born between 1963 and 1974, were included; these individuals were born before China's reformation when nationwide economic development began.

\section{Results}

Characteristics of the exposed and unexposed participants in the severely and moderately affected famine areas The characteristics of the exposed and unexposed participants in the severely and moderately affected famine areas are summarised in Table 1. Compared with the participants in the moderately affected area, the fetal- and childhoodexposed participants in the severely affected area were 1 year older, due to our survey time, and they had a significantly higher education level and a higher $\operatorname{HbA}_{1 \mathrm{c}}(p<0.05)$. The fetal-exposed participants also had a $2.6 \mathrm{~cm}$ greater waist circumference $(p<0.05)$. However, we found that the unexposed participants were not significantly different from the famineexposed participants in this regard.

Prevalence of diabetes and life stage during famine exposure The prevalence of diabetes in the unexposed group and groups exposed to famine during the fetal stage, childhood and adolescence/adulthood was $9.8 \%, 22.6 \%, 26.0 \%$ and $24.5 \%$, respectively, in the severely affected area and $5.7 \%$, $11.2 \%, 19.0 \%$ and $18.6 \%$, respectively, in the moderately affected area (Fig. 2). Compared with the participants in the moderately affected area, the fetal- and childhood-exposed participants in the severely affected area had a significantly higher prevalence of diabetes (both $p<0.05$, adjusted for age, sex, current smoking status, education level and waist circumference). However, the unexposed participants in the severely and moderately affected areas had a comparable prevalence of diabetes. Information of the number of cases of diabetes and sample size, collected at 2 year intervals, is shown in electronic supplementary material (ESM) Table 1.

DID estimates of the effect of severe famine exposure on $\mathrm{HbA}_{1 \mathrm{c}}$ and FPG in adulthood Tables 2 and 3 present DID estimates for $\mathrm{HbA}_{1 \mathrm{c}}$ and $\mathrm{FPG}$ in all of the participants and in participants not taking glucose-lowering drugs. The individuals exposed to famine during the fetal stage, childhood and adolescence/adulthood living in a severely affected area had a $0.31 \%, 0.20 \%$ and $0.27 \%$ higher $\mathrm{HbA}_{1 \mathrm{c}}$, respectively, (all $p<0.01$ ), compared with the unexposed individuals. Similarly, in participants not taking glucose-lowering drugs, the fetal-, childhood- and adolescence/adult-exposed individuals living in a severely affected area had a $0.22 \%, 0.15 \%$ and $0.34 \%$ higher $\mathrm{HbA}_{1 \mathrm{c}}$, respectively (all $p<0.01$ ). However, the association between FPG and living in a severely affected area was not significant in any of the participants whether or not they were taking glucose-lowering drugs.

Table 1 Characteristics of the famine-exposed and unexposed individuals in the severely and moderately affected areas

\begin{tabular}{|c|c|c|c|c|c|c|c|c|}
\hline \multirow[t]{2}{*}{ Characteristic } & \multicolumn{2}{|c|}{$\begin{array}{l}\text { Unexposed } \\
\text { (birth year 1963-1997) }\end{array}$} & \multicolumn{2}{|c|}{$\begin{array}{l}\text { Fetal-exposed } \\
\text { (birth year 1959-1962) }\end{array}$} & \multicolumn{2}{|c|}{$\begin{array}{l}\text { Childhood-exposed } \\
\text { (birth year 1949-1958) }\end{array}$} & \multicolumn{2}{|c|}{$\begin{array}{l}\text { Adolescence-exposed } \\
\text { (birth year 1926-1948) }\end{array}$} \\
\hline & $\begin{array}{l}\text { Severely } \\
\text { affected area }\end{array}$ & $\begin{array}{l}\text { Moderately } \\
\text { affected area }\end{array}$ & $\begin{array}{l}\text { Severely } \\
\text { affected area }\end{array}$ & $\begin{array}{l}\text { Moderately } \\
\text { affected area }\end{array}$ & $\begin{array}{l}\text { Severely } \\
\text { affected area }\end{array}$ & $\begin{array}{l}\text { Moderately } \\
\text { affected area }\end{array}$ & $\begin{array}{l}\text { Severely } \\
\text { affected area }\end{array}$ & $\begin{array}{l}\text { Moderately } \\
\text { affected area }\end{array}$ \\
\hline$N$ & 981 & 651 & 230 & 259 & 530 & 610 & 368 & 338 \\
\hline Age, years & $44 \pm 6$ & $41 \pm 8^{*}$ & $54 \pm 1$ & $53 \pm 1 *$ & $62 \pm 3$ & $61 \pm 3^{*}$ & $71 \pm 4$ & $72 \pm 5$ \\
\hline Men & 36.6 & 35.3 & 35.7 & 40.2 & 47.4 & 42.3 & 61.4 & $43.2 *$ \\
\hline Current smoker & 16.3 & 19.2 & 22.0 & 27.3 & 23.8 & 24.5 & 31.7 & $17.6^{*}$ \\
\hline \multicolumn{9}{|l|}{ Level of education } \\
\hline Low & 70.9 & 88.1 & 92.8 & 98.8 & 96.9 & 99.6 & 97.8 & 98.4 \\
\hline High & 29.1 & $11.9^{*}$ & 7.2 & $1.2 *$ & 3.1 & $0.4^{*}$ & 2.2 & 1.6 \\
\hline $\mathrm{WC}, \mathrm{cm}$ & $80.8 \pm 10.3$ & $77.4 \pm 10.1^{*}$ & $84.1 \pm 9.2$ & $81.5 \pm 9.7^{*}$ & $84.9 \pm 9.4$ & $83.8 \pm 9.4$ & $87.5 \pm 10.6$ & $84.6 \pm 10.0 *$ \\
\hline $\mathrm{HbA}_{1 \mathrm{c}}, \%$ & $5.5 \pm 0.9$ & $5.1 \pm 0.8^{*}$ & $6.0 \pm 1.2$ & $5.3 \pm 0.8^{*}$ & $6.1 \pm 1.2$ & $5.6 \pm 1.0^{*}$ & $6.2 \pm 1.2$ & $5.5 \pm 0.9^{*}$ \\
\hline $\mathrm{HbA}_{1 \mathrm{c}}, \mathrm{mmol} / \mathrm{mol}$ & $37.0 \pm 9.8$ & $32.0 \pm 9.2 *$ & $42.5 \pm 12.7$ & $34.8 \pm 9.2 *$ & $43.6 \pm 12.7$ & $37.3 \pm 10.7^{*}$ & $44.1 \pm 13.0$ & $36.3 \pm 9.8^{*}$ \\
\hline $\mathrm{FPG}, \mathrm{mmol} / 1$ & $5.38 \pm 1.41$ & $5.48 \pm 1.40$ & $5.79 \pm 1.92$ & $5.85 \pm 1.46$ & $5.91 \pm 1.70$ & $6.12 \pm 1.65^{*}$ & $5.99 \pm 1.89$ & $6.04 \pm 1.54$ \\
\hline
\end{tabular}

Continuous variables are expressed as the mean $\pm \mathrm{SD}$ and categorical variables are presented as $\%$

When comparing differences, Mann-Whitney $U$ test and Student's $t$ test were used for continuous variables with a skewed distribution and a normal distribution, respectively, and the Pearson $\chi^{2}$ test was used for categorical variables

$* p<0.05$ compared with individuals in the severely affected area

WC, waist circumference 


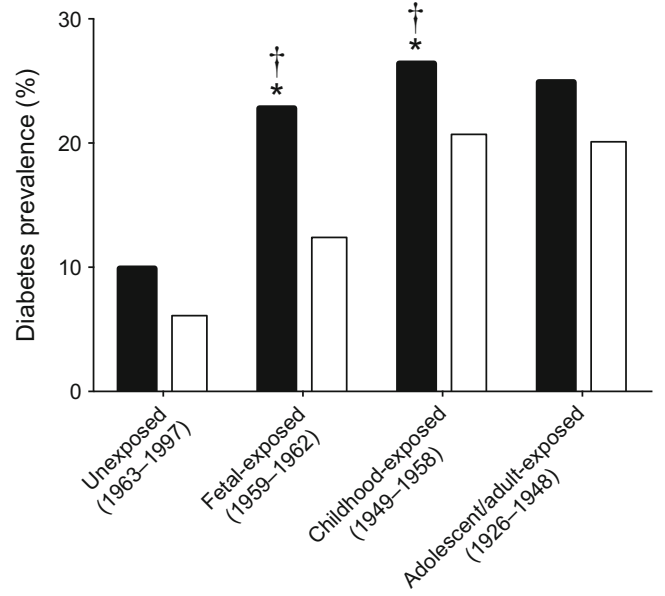

Fig. 2 Prevalence of diabetes in severely and moderately affected areas of famine. Birth year of participants is given in parentheses. ${ }^{*} p<0.05$ compared with the corresponding moderately affected area, adjusted for age, sex, current smoking status, education level and waist circumference. ${ }^{\dagger} p<0.05$, significant interaction effects between famine-affected areas and different life stages of famine exposure. Black bars, severely affected area; white bars, moderately affected area

\section{Association between the severity of famine exposure and} the risk of developing diabetes in adulthood Table 4 presents the associations between the severity of famine exposure and the prevalence of diabetes in exposed and unexposed participants. After adjusting for age, sex, current smoking and education level, exposure to severe famine during the fetal stage (OR 2.44, 95\% CI 1.45, 4.08), childhood (OR 1.40, 95\% CI $1.04,1.89$ ) and adolescence/adulthood (OR 1.59, 95\% CI 1.08, 2.36) was associated with significantly greater prevalence estimates. After also adjusting for waist circumference, the ORs were $1.90(1.12,3.21)$ and $1.44(1.06,1.97)$ in the fetal- and childhood-exposed participants, respectively. For participants exposed to severe famine during adolescence/adulthood, if we adjusted for waist circumference, the association weakened such that it was no longer statistically significant (OR 1.38, 95\% CI 0.91, 2.10). The unexposed participants living in the severely and moderately affected areas had comparable diabetes ORs in all three models (OR 1.42 [95\% CI 0.95, 2.13] in model 1; OR 1.41 [95\% CI 0.93, 2.14] in model 2; OR 1.22, [95\% CI $0.80,1.87]$ in model 3). A significant interaction between famine exposure and the areas was found only for the groups exposed during the fetal stage and childhood $(p<0.05)$.
In sensitivity analyses using finer age categories (ESM Table 2), individuals exposed to famine during the fetal stage (OR 2.10, 95\% CI 1.21, 3.63) and late childhood (OR 1.76, 95\% CI $1.14,2.72)$ in a severely affected area still had significantly greater prevalence estimates in the final model. In the unexposed participants, the risk of developing diabetes was not significantly different for the severely and moderately affected areas.

\section{Discussion}

We found that exposure to severe famine vs moderately severe famine during the fetal stage increased the odds of developing diabetes as an adult by 1.6-fold (1.90/1.22), whereas exposure during childhood increased the odds by 1.2-fold (1.44/1.22). Using DID models, we also found that prenatal or postnatal exposure to more severe famine increased $\mathrm{HbA}_{1 \mathrm{c}}$ by $0.20-0.31$ when the individuals were aged 50 years or older. Combined with the results of our previous study [5], these results indicate that both prenatal and postnatal life stages may be important time windows for determining the future risk of diabetes.

Our previous study evaluated participants from three areas with comparable and moderate famine severity in China to analyse whether exposure to famine early in life was associated with diabetes later in life [5]. We found that, compared with unexposed participants, famine exposure during the fetal period (OR 1.53, 95\% CI 1.09, 2.14) and childhood period (OR 1.82, 95\% CI 1.21, 2.73) was associated with diabetes [5]. However, a limitation of that study was the lack of quality data for the famine and non-famine exposure groups. In the present study, we added three sites from Anhui Province, one with the most severe famine exposure, allowing us to address the association between the severity of famine exposure early in life and the prevalence of adult diabetes. We further compared the unexposed participants in the severely and moderately affected areas and found that they had comparable diabetes risks, which reinforces our conclusions regarding the effect of famine on diabetes risk.

Lumey et al reported that prenatal exposure to extreme famine in eastern Ukraine in 1934 increased the odds of developing type 2 diabetes in adulthood by 1.5 -fold [4]. Another study found that postnatal exposure to severe famine in a
Table 2 DID estimates of prenatal or postnatal exposure to severe famine on $\mathrm{HbA}_{1 \mathrm{c}}$ in adulthood, based on ordinary least-square regressions

\begin{tabular}{lllll}
\hline Characteristic & Fetal-exposed & Childhood-exposed & Adolescence/adult-exposed & Unexposed \\
\hline $\mathrm{HbA}_{1 \mathrm{c}}$ & $0.31(0.13,051)^{* *}$ & $0.20(0.05,0.35)^{* *}$ & $0.27(0.09 .0 .44)^{* *}$ & Ref. \\
$\log _{e} \mathrm{FPG}$ & $0.00(-0.04,0.04)$ & $-0.00(-0.04,0.03)$ & $0.01(-0.03,0.04)$ & Ref. \\
\hline
\end{tabular}

Data are presented as coefficients $(95 \% \mathrm{CI})$. The model included terms for age, sex, current smoking status, education level and waist circumference

Ref., reference (the unexposed)

$* * p<0.01$ vs the unexposed 
Table 3 DID estimates of prenatal or postnatal exposure to severe famine on $\mathrm{HbA}_{1 \mathrm{c}}$ in adulthood, based on ordinary least-square regressions, excluding individuals taking glucose-lowering drugs

\begin{tabular}{lllll}
\hline Characteristic & Fetal-exposed & Childhood-exposed & Adolescence/adult-exposed & Unexposed \\
\hline $\mathrm{HbA}_{1 \mathrm{c}}$ & $0.22(0.07,0.38)^{* *}$ & $0.15(0.03,0.28)^{* *}$ & $0.34(0.18 .0 .49)^{* *}$ & Ref. \\
$\mathrm{Log}_{e} \mathrm{FPG}$ & $-0.02(-0.05,0.02)$ & $-0.01(-0.04,0.02)$ & $0.02(-0.01,0.05)$ & Ref. \\
\hline
\end{tabular}

Data are presented as coefficients $(95 \% \mathrm{CI})$. The model included terms for age, sex, current smoking status, education level and waist circumference

Ref., reference (the unexposed)

$* * p<0.01$ vs the unexposed
Dutch population increased diabetes risk in women by 1.5 fold [8]. In this study, we were able to compare the effects of both prenatal and postnatal exposure to different levels of famine severity on the risk of developing diabetes in the same population. Our findings are in accordance with those of the two studies mentioned above and with the results of our previous study [5]. These findings suggest not only is the fetal stage a particularly vulnerable period for malnutrition reprogramming but also that childhood (0-9 years old) is a vulnerable period. This study supports the developmental origins of health and disease hypothesis $[16,17]$ and indicates that the adverse effects of famine exposure may extend beyond the 'first 1000 days' $[8,18]$.

Regarding potential mechanisms underlying this association, we are increasingly aware that epigenetic changes have important relevance. A study that evaluated whole blood from Dutch participants who had been exposed to famine during the prenatal period reported that regions of differential methylation extended along pathways related to growth and metabolism [19]. Epigenetic plasticity may also extend into the postnatal life stage, leading to the proposition of 'metabolic imprinting' as the biological phenomenon that underlies the associations between nutritional events early in life and metabolic diseases later in life [20,21]. However, the epigenetic studies of childhood exposure to energy restriction are limited and findings need to be confirmed. Furthermore, bioinformatics studies indicate that perinatal malnutrition could permanently alter the expression of gene clusters that regulate insulin signalling and nutrient sensing, and this could affect the detection and use of lipid nutrients as fuel [22]. Additionally, adult offspring from mothers who underwent protein restriction experienced age-related impairment of glucose tolerance and a loss of insulin sensitivity in adipose tissue as well as an increase in proinflammatory markers [23-25]. A better understanding of this association requires additional studies.

In logistic analyses, we adjusted for age and sex in the base model. Low educational level (socioeconomic status proxy) and smoking status may be important risk factors for diabetes $[8,26]$. However, the adjustment for such risk factors yielded very slight or almost no change in risk estimates. Previous studies suggested that waist circumference was an important covariate linking famine exposure early in life to the development of type 2 diabetes later in life [8]. In our study, we also found that adjusting for waist circumference attenuated the risk

Table 4 Prenatal or postnatal exposure to the different severities of famine and the risk of developing diabetes later in life

\begin{tabular}{|c|c|c|c|c|c|}
\hline $\begin{array}{l}\text { Life stage when } \\
\text { exposed to famine }\end{array}$ & No. cases/sample size & Model 1 & Model 2 & Model 3 & $\begin{array}{l}p \text { for interaction between } \\
\text { areas and exposed groups }\end{array}$ \\
\hline \multicolumn{6}{|l|}{ Unexposed } \\
\hline Severely affected area & $96 / 981$ & $1.42(0.95,2.13)$ & $1.41(0.93,2.14)$ & $1.22(0.80,1.87)$ & \\
\hline Moderately affected area & $37 / 651$ & 1.00 (Ref.) & 1.00 (Ref.) & 1.00 (Ref.) & \\
\hline \multicolumn{6}{|l|}{ Fetal stage } \\
\hline Severely affected area & $52 / 230$ & $2.41(1.46,3.97)^{*}$ & $2.44(1.45,4.08) *$ & $1.90(1.12,3.21)^{*}$ & \multirow[t]{2}{*}{$<0.05$} \\
\hline Moderately affected area & $29 / 259$ & 1.00 (Ref.) & 1.00 (Ref.) & 1.00 (Ref.) & \\
\hline \multicolumn{6}{|l|}{ Childhood } \\
\hline Severely affected area & $138 / 530$ & $1.42(1.07,1.89)^{*}$ & $1.40(1.04,1.89) *$ & $1.44(1.06,1.97)^{*}$ & \multirow[t]{2}{*}{$<0.05$} \\
\hline Moderately affected area & $116 / 610$ & 1.00 (Ref.) & 1.00 (Ref.) & 1.00 (Ref.) & \\
\hline \multicolumn{6}{|l|}{ Adolescence/adulthood } \\
\hline Severely affected area & $90 / 368$ & $1.60(1.10,2.33)^{*}$ & $1.59(1.08,2.36)^{*}$ & $1.38(0.91,2.10)$ & \multirow[t]{2}{*}{0.86} \\
\hline Moderately affected area & $63 / 338$ & 1.00 (Ref.) & 1.00 (Ref.) & 1.00 (Ref.) & \\
\hline
\end{tabular}

Data are presented as OR $(95 \% \mathrm{CI})$, calculated by logistic regression models (backward stepwise). Interaction effects between areas and exposed groups were measured in model 3. Model 1 included terms for age and sex. Model 2 included terms for model 1, current smoking status and education level. Model 3 included terms for model 2 and waist circumference

$* p<0.05$ vs moderately affected area 
estimates in participants exposed to famine during the fetal stage and adolescence/adulthood. Moreover, in the participants exposed to famine during adolescence/adulthood, the association weakened such that it was no longer significant. Because abdominal obesity could be induced by malnutrition early in life [27] and could also cause diabetes [28], waist circumference accounted for the majority of the association between famine severity and diabetes risk in participants exposed to famine during adolescence/adulthood but only partially explained the association in participants exposed during the fetal period.

An unexpected finding was that participants in the severe famine area appeared to have attained a higher level of education than those in the moderate famine area. In our study, a portion of participants in the severe famine area attended functional communities such as schools, which may have increased the proportion of individuals attaining a high education level. This observation indicates that severe famine exposure does not necessarily lead to low socioeconomic status [15]. After excluding individuals reaching a high level of education (a relatively small sample) from our data, our findings were not significantly changed (ESM Table 3).

Our study has some strengths, including a strong quality control due to the inclusion of areas with different levels of famine severity and the adjustment for important covariates. Anthropometric measurements and questionnaires were all completed by individuals in the same trained research group, thus providing strong quality control. This study also added value to previous studies. The association between famine and diabetes was not fully addressed in previous studies because of the inclusion of only women, the limited evaluation of either prenatal or postnatal exposure or the inclusion of regions without different famine severities. To help tackle these problems, we evaluated participants exposed to China's Great Famine of 1959-1962. These data included both sexes, prenatal and postnatal famine exposure and different levels of famine severity. We also performed interaction analyses and used DID models and finer age categorisation to consolidate our findings. Thus, our study provides objective and possibly unique evidence to support the notion of an association between diabetes and prenatal or postnatal exposure to famine in areas with different levels of famine severity.

There are also some limitations to this study. We did not include other possible confounders such as birthweight or the avoidance of famine exposure because of social status. However, before China's reform, the Chinese government pursued an egalitarian policy and the standard of living was low. Any greater access to food was probably limited to a very small portion of the population so this might not significantly affect the results of this large study. Finally, we were unable to include a group that was not affected by the famine for comparison. However, because China's Great Famine affected all of the areas in China [29], identifying a location where people did not suffer from famine may not be feasible.
Migrations could be another potential problem. We enrolled residents who had lived in their current residence for 6 months or longer. It is assumed that they were born in the local area and did not move from other areas. This assumption might lead to biased estimates of famine effects. However, although population mobility is increasing with economic development in China, acquisition of permanent residency has strict requirements and must be approved by the Chinese government. According to a national investigation, approximately $97 \%$ of the rural population still lived in the place in which they were born [7]. Moreover, the exposed participants in our study are close to retirement age, so they are less likely to be mobile than younger individuals. Therefore, the small proportion of migration that occurred may not have affect the overall results.

In conclusion, we noted that exposure to severe famine during the fetal period and childhood was significantly associated with increased $\mathrm{HbA}_{1 \mathrm{c}}$ and higher diabetes prevalence in adulthood. Combined with the results of our previous study [5], these results from China indicate that the prenatal and postnatal life stages may provide a critical timing window for determining the risk of diabetes, at least in part.

Acknowledgements The authors thank X. Wang and B. Wang from the Department of Biostatistics, Shanghai JiaoTong University School of Medicine, Shanghai, China, for data processing and W. Tu, B. Li and L. $\mathrm{Hu}$ for helping to organise this investigation.

The authors thank all team members and participants from Shanghai and Anhui Province.

Funding This study was supported by funding from the National Natural Science Foundation of China (81270885, 81570726), the Shanghai JiaoTong University School of Medicine (2014), the Ministry of Science and Technology in China (2012CB524906) and the Science and Technology Commission of Shanghai Municipality (14495810700, 16410723200).

Duality of interest The authors declare that there is no duality of interest associated with this manuscript.

Contribution statement YL and MDJ designed the research, NW analysed the data and NW and YL wrote the manuscript. All authors were involved in the acquisition and/or interpretation of the data, critically revised the manuscript for important intellectual content and gave their final approval to the version to be published. YL is the guarantor of this work.

\section{References}

1. Danaei G, Lawes CM, Vander Hoorn S, Murray CJ, Ezzati M (2006) Global and regional mortality from ischaemic heart disease and stroke attributable to higher-than-optimum blood glucose concentration: comparative risk assessment. Lancet 368:1651-1659

2. Danaei G, Finucane MM, Lu Y et al (2011) National, regional, and global trends in fasting plasma glucose and diabetes prevalence 
since 1980: systematic analysis of health examination surveys and epidemiological studies with 370 country-years and 2.7 million participants. Lancet 378:31-40

3. Xu Y, Wang L, He J et al (2013) Prevalence and control of diabetes in Chinese adults. JAMA 310:948-959

4. Lumey LH, Khalangot MD, Vaiserman AM (2015) Association between type 2 diabetes and prenatal exposure to the Ukraine famine of 1932-33: a retrospective cohort study. Lancet Diabetes Endocrinol 3:787-794

5. Wang N, Wang X, Han B et al (2015) Is exposure to famine in childhood and economic development in adulthood associated with diabetes? J Clin Endocrinol Metab 100:4514-4523

6. Wang N, Chen Y, Ning Z et al (2016) Exposure to famine in early life and nonalcoholic fatty liver disease in adulthood. J Clin Endocrinol Metab 101:2218-2225

7. Li Y, He Y, Qi L et al (2010) Exposure to the Chinese famine in early life and the risk of hyperglycemia and type 2 diabetes in adulthood. Diabetes 59:2400-2406

8. van Abeelen AF, Elias SG, Bossuyt PM et al (2012) Famine exposure in the young and the risk of type 2 diabetes in adulthood. Diabetes 61:2255-2260

9. Zheng X, Wang Y, Ren W et al (2012) Risk of metabolic syndrome in adults exposed to the great Chinese famine during the foetal life and early childhood. Eur J Clin Nutr 66:231-236

10. Barker DJ, Osmond C, Kajantie E, Eriksson JG et al (2009) Growth and chronic disease: findings in the Helsinki Birth Cohort. Ann Hum Biol 36:445-458

11. Mu R, Zhang X (2011) Why does the Great Chinese famine affect the male and female survivors differently? Mortality selection versus son preference. Econ Hum Biol 9:92-105

12. Johnson DG (1998) China s great famine: introductory remarks. China Econ Rev 9:103-109

13. Wang N, Wang X, Li Q et al (2015) The famine exposure in early life and metabolic syndrome in adulthood. Clin Nutr. doi:10.1016/j. clnu.2015.11.010

14. Luo Z, Mu R, Zhang X (2006) Famine and overweight in China. Rev Agric Econ 28:296-304

15. Fan W, Qian Y (2015) Long-term health and socioeconomic consequences of early-life exposure to the 1959-1961 Chinese Famine. Soc Sci Res 49:53-69
16. Gillman MW, Barker D, Bier D et al (2007) Meeting report on the 3rd International Congress on Developmental Origins of Health and Disease (DOHaD). Pediatr Res 61:625-629

17. Uauy R, Kain J, Corvalan C (2011) How can the Developmental Origins of Health and Disease (DOHaD) hypothesis contribute to improving health in developing countries? Am J Clin Nutr 94: 1759S-1764S

18. Khoroshinina LP, Zhavoronkova NV (2008) Starving in childhood and diabetes mellitus in elderly age. Adv Gerontol 21:684-687

19. Tobi EW, Goeman JJ, Monajemi R et al (2014) DNA methylation signatures link prenatal famine exposure to growth and metabolism. Nat Commun 5:5592

20. Hochberg Z, Feil R, Constancia M et al (2011) Child health, developmental plasticity, and epigenetic programming. Endocr Rev 32: 159-224

21. Waterland RA, Garza C (1999) Potential mechanisms of metabolic imprinting that lead to chronic disease. Am J Clin Nutr 69:179-197

22. Orozco-Solís R, Matos RJ, Guzmán-Quevedo O et al (2010) Nutritional programming in the rat is linked to long-lasting changes in nutrient sensing and energy homeostasis in the hypothalamus. PLoS One 5:e13537

23. Akasheh RT, Pang J, York JM, Fantuzzi G (2013) New pathways to control inflammatory responses in adipose tissue. Curr Opin Pharmacol 13:613-617

24. Ozanne SE, Dorling MW, Wang CL, Nave BT (2001) Impaired PI 3-kinase activation in adipocytes from early growth-restricted male rats. Am J Physiol Endocrinol Metab 280:E534-E539

25. Lukaszewski MA, Eberlé D, Vieau D, Breton C (2013) Nutritional manipulations in the perinatal period program adipose tissue in offspring. Am J Physiol Endocrinol Metab 305:E1195-E1207

26. Cho NH, Chan JC, Jang HC, Lim S, Kim HL, Choi SH (2009) Cigarette smoking is an independent risk factor for type 2 diabetes: a four-year community-based prospective study. Clin Endocrinol (Oxf) 71:679-685

27. Ravelli AC, van Der Meulen JH, Osmond C, Barker DJ, Bleker OP (1999) Obesity at the age of $50 \mathrm{y}$ in men and women exposed to famine prenatally. Am J Clin Nutr 70:811-816

28. Xue H, Wang C, Li Y et al (2016) Incidence of type 2 diabetes and number of events attributable to abdominal obesity in China: a cohort study. J Diabetes 8:190-198

29. Lin JY, Yang DT (2000) Food availability, entitlements and the Chinese Famine of 1959-61. Econ J 460:136-158 